\title{
Acute spontaneous intracerebral hemorrhage and traumatic brain injury are the most common causes of critical illness in the ICU and have high early mortality
}

Ye-Ting Zhou ${ }^{1+}$, Dao-Ming Tong ${ }^{2 *+}$, Shao-Dan Wang ${ }^{3}$, Song Ye ${ }^{1}$, Ben-Wen Xu ${ }^{1}$ and Chen-Xi Yang ${ }^{1}$

\begin{abstract}
Background: Critical care covers multiple disciplines. However, the causes of critical illness in the ICU, particularly the most common causes, remain unclear. We aimed to investigate the incidence and the most common causes of critical illness and the corresponding early mortality rates in ICU patients.

Methods: A retrospective cohort study was performed to examine critically ill patients (aged over 15 years) in the general ICU in Shuyang County in northern China (1/2014-12/2015). The incidences and causes of critical illnesses and their corresponding early mortality rates in the ICU were determined by an expert panel.

Results: During the 2-year study period, 1,211,138 person-years (PY) and 1645 critically ill patients (mean age, 61.8 years) were documented. The median Glasgow Coma Scale (GCS) score was 6 (range, 3-15). The mean acute physiology and chronic health evaluation II (APACHE II) score was 21.2 \pm 6.8 . The median length of the ICU stay was 4 days (range, 1-29 days). The most common causes of critical illness in the ICU were spontaneous intracerebral hemorrhage (SICH) (26\%, 17.6/100,000 PY) and traumatic brain injury (TBI) $(16.8 \%, 11.4 / 100,000$ PY). During the first 7 days in the ICU, SICH was the most common cause of death (42.2\%, 7.4/10,000 PY), followed by TBI (36.6\%, 4.2/100,000 PY). Based on a logistic analysis, older patients had a significantly higher risk of death from TBI (risk ratio $[R R], 1.7 ; 95 \% \mathrm{Cl}, 1.034-2.635)$, heart failure/cardiovascular crisis (RR, $0.2 ; 95 \% \mathrm{Cl}, 0.083-0.484)$, cerebral infarction ( $R R, 0.15 ; 95 \% \mathrm{Cl}, 0.050-0.486)$, or respiratory failure (RR, $0.35 ; 95 \% \mathrm{Cl}, 0.185-0.784)$ than younger patients. However, the risk of death from $\mathrm{SICH}$ in the two groups was similar.
\end{abstract}

Conclusions: The most common causes of critical illness in the ICU were SICH and TBI, and both critical illnesses showed a higher risk of death during the first 7 days in the ICU.

Keywords: Critical illness, Causes, Incidence, Mortality, Epidemiology, Intracerebral hemorrhage, Head injury

\section{Background}

Twenty years ago, patients with organ failure accounted for most intensive care unit (ICU) cases [1], and a high mortality rate was observed in patients who refused ICU care $[2,3]$. Today, with improvements in living standards and the aging of the general population, management of critically ill patients using intensive nursing care is more

\footnotetext{
* Correspondence: dmtong@xzhmu.edu.cn

${ }^{\dagger}$ Ye-Ting Zhou and Dao-Ming Tong contributed equally to this work.

${ }^{2}$ Department of Neurology, Affiliated Shuyang Hospital, Xuzhou Medical University, Xuzhou, Jiangsu, China

Full list of author information is available at the end of the article
}

common [4-6]. Multiple epidemiological studies on prehospital emergency medical services have been conducted [7, 8]; however, the causes of critical illnesses in the ICU, especially the most common causes, remain unclear. Moreover, it is important to determine the most common illnesses that require management in an ICU and to understand the early mortality rates associated with these illnesses during the ICU stay. The aim of this study was to investigate the incidences and causes of critical illnesses and the corresponding early mortality rates among patients admitted to the ICU from the general population of Shuyang County in northern China. 


\section{Methods}

\section{Study design and participants}

We retrospectively analyzed data that were collected from January 2014 to December 2015 for critically ill patients who were admitted to a general ICU (17 beds) in a tertiary teaching hospital-the unique three-general hospital. The hospital has a referral center (with 10 ambulances) and was responsible for all critical or emergency work within Shuyang County in northern China (38 county townships and a county town). Thus, $24 \mathrm{~h}$ a day, almost all critically ill patients were sent directly to the ICU. Therefore, this hospital was a strong source of critically ill patients, which ensured sufficient data availability. The study sample was compiled from the 2014 and 2015 data registries. During the study period, $1,211,138$ people aged 15 years or older, including 697,615 women and 115,355 people aged 65 years or older, lived in the county [9]. The study was approved by the Ethical Committee on Clinical Research of the Shuyang People's Hospital in China. Because the study involved care for critical illness, written informed consent was obtained from the nearest relative or a person who had been designated to provide consent by the patient.

\section{Procedures}

To date, there are no compulsory diagnostic criteria for critical illness. Moreover, the codes for critical illnesses per the International Classification of Diseases, 10th Revision (ICD-10), are not well established. The relevant code changes according to the condition of the critically ill patient, and these conditions include coma (R40.2), cardiac arrest (I46.9), heart failure (I50), shock (R57.9), respiratory failure (J96), cardiovascular crisis and other critical events. We also identified those patients who had acute spontaneous intracerebral hemorrhage $(\mathrm{SICH})$ by the code I61.9, but in this study, SICH was only limited to those with acutely non-traumatic coma. Similarly, traumatic brain injury (TBI) indicated a severe TBI (including traumatic subdural and epidural hematoma, or with intracerebral hematoma or subarachnoid hemorrhage) with sudden traumatic coma. Coma refers to a state of unconsciousness from which the patient cannot be aroused and is typified by the absence of language and motor function with a Glasgow Coma Scale (GCS) score of 3 to 8 (on a scale of 3 to 15, with lower scores indicating a lower level of consciousness). Cardiovascular crisis includes cardiogenic shock, cardiac arrest, sudden chest pain, and hypertensive crisis. Here, our retrospective study of ICU patients used the following inclusion criteria: (1) the patient (age $>15$ years) exhibited an emergency- onset condition with unstable life signs or acute organ dysfunction and required transfer by emergency services to the ICU, and (2) the patient was hospitalized due to the onset a life-threatening organ dysfunction and required monitoring in the ICU. We used the following exclusion criteria: (1) age $<15$ years, (2) an additional visit to the ICU within 2 weeks, and (3) residence in the county for $<6$ months. We collected the critically ill patient data from the prospective registration of their primary diagnosis in the ICU patient out-of-hospital registry. Registration was the responsibility of the physician in charge of the ICU. The data registry annual volumes included sex, age, address, the date of admission, the sole primary diagnosis, the ICU stay length, the outcome of the main processing, and a contact telephone number for the ICU patient. All patients with craniocerebral disease were verified using their electronic medical records (an emergency cranial CT scan upon admission) and were assigned an initial GCS score and an acute physiology and chronic health evaluation II (APACHE II) score.

The time window of the ICU stay for most patients was between 3 and 7 days. Early mortality was assessed during the first 7 days of the critical illness. The World Health Organization (WHO) defines a person who is over 65 years old as geriatric. Therefore, patients were divided into a geriatric group and a non-geriatric group to compare the risks of critical illness between age groups.

Death events in the ICU and their causes were identified through medical record notes and from follow-up information. Follow-up information was from our physician who was conducted inquiries by phone to the patient's closest living relative on day 7 of discharge from the ICU. Intensive care and neurology experts conducted a retrospective statistical analysis of the data of the study population during the 2-year period.

\section{Statistical analysis}

All numeric variables are expressed as the mean \pm SD or median (interquartile range [IQR]) and $\mathrm{N}(\%)$. The overall incidence and causes were analyzed. The incidence rate per year in the population of critically ill patients was documented. Incidence rates for risk during 1 year were also calculated by dividing the baseline population by the number of annual cases. We used a logistic regression analysis to determine the risk ratio (RR) for a death event comparing the geriatric patients with the non-geriatric patients. All $p$-values were 2 -sided, and significance was set at $p<0.05$. Data were analyzed using SPSS version 17.0 (SPSS Inc., Chicago, IL, USA).

\section{Results}

\section{Overall analysis}

During the 2-year study period, 1791 critically ill cases were registered in the ICU following hospital discharge. We excluded cases that did not meet the inclusion criteria, including patients aged $<15$ years $(n=126)$, patients who had another visitation to the ICU within 
2 weeks $(n=21)$, and patients who had lived in the area for $<6$ months $(n=4)$. Ultimately, 1645 patients who met the criteria were designated as critically ill patients and were enrolled into the study. The survey included 1015 men (61.7\%) and 630 women (38.3\%), which resulted in a male-to-female ratio of 1.7:1. The ages of the patients ranged from 15 to 98 years, and the average age was $61.8 \pm 0.49$ years. The median initial GCS score was 6 (range, 3-15). The mean initial APACHE II score (mean $\pm \mathrm{SD}$ ) was $21.2 \pm 6.8$. The median length of the ICU stay was 4 days (up to 29 days).

\section{Incidence of critical illness}

During the 2-year study period, 1645 patients with an acute critical illness were documented among the total county population. The total incidence of critical illness was 67.9/100,000 person-years (PY) (Table 1). The most common acute critical illness types were strokes and neurological critical illnesses (632/2 years, 38.4\%, 26.1/ 100,000 PY, including 577 cases of stroke/2 years, 35.1\%, $23.8 / 100,000 \mathrm{PY})$, followed by trauma and traumatic brain injury (TBI) (397/2 years, 24.1\%, 16.4/100,000 PY), cardiovascular critical diseases (140/2 years, 5.8/100,000 PY), and respiratory critical diseases ( $96 / 2$ years, 4.0/ 100,000 PY).

The incidence of acute SICH tended to increase with increasing age, with the incidence peaking between 55 and 64 years. The incidence of TBI tended to decrease with decreasing age, with the incidence peaking between 65 and 74 years. The types and outcome of SICH and TBI during the first 7 days in the ICU are shown in Table 2.

Table 1 Incidence and ranking of emergency critical events

\begin{tabular}{llll}
\hline Critically ill events ranking & $\begin{array}{l}\text { Number } \\
\text { of cases } \\
\text { in 2 years }\end{array}$ & Percentage (\%) & $\begin{array}{l}\text { Per100000 } \\
\text { population } \\
\text { members } \\
\text { per year }\end{array}$ \\
\hline $\begin{array}{l}\text { Stroke and neurological } \\
\text { critical ill }\end{array}$ & 632 & 38.4 & 26.1 \\
TBl and Trauma & 397 & 24.1 & 16.4 \\
Cardiovascular Critical ill & 140 & 8.5 & 5.8 \\
Respiratory Critical ill & 96 & 5.8 & 4.0 \\
After surgery or intervention & 89 & 5.4 & 3.7 \\
Gastrointestinal critical ill & 74 & 4.5 & 3.1 \\
Pesticides / drug poisoning & 72 & 4.4 & 3.0 \\
Sepsis / septic shock & 48 & 2.9 & 2.0 \\
Any cancer & 32 & 1.9 & 1.3 \\
Others & 65 & 4.0 & 2.7 \\
All & 1645 & 100 & 67.9 \\
\hline
\end{tabular}

TBI traumatic brain injury
Table 2 The types and outcome of SICH and TBI observed during the first 7 days in the ICU

\begin{tabular}{lll}
\hline Types & $\begin{array}{l}\text { Number of } \\
\text { cases in 2 years }\end{array}$ & Death (\%) \\
\hline SICH & 427 & $180(42.2)$ \\
Striato-capsula,n(\%) & $178(41.7)$ & $75(42.1)$ \\
Lobar,n(\%) & $81(10.0)$ & $30(37.0)$ \\
Thalamus,n(\%) & $72(16.7)$ & $23(31.9)$ \\
Brainstem, n(\%) & $61(14.3)$ & $40(65.6)$ \\
Cerebellar, n(\%) & $26(6.1)$ & $10(38.5)$ \\
Others (\%),n(\%) & $9(2.1)$ & $2(22.0)$ \\
TBI & 276 & $101(36.6)$ \\
Subdural hematoma, n(\%) & $181(65.6)$ & $89(49.2)$ \\
Intracerebral hemorrhage, n(\%) & $58(21.0)$ & $9(15.5)$ \\
Epideural hematoma, n(\%) & $37(13.4)$ & $3(8.1)$ \\
With subarachnoid hemorrhage, n(\%) & $201((72.8))$ & N/A \\
With contusions, n(\%) & $189(68.5)$ & N/A \\
With fractures, n(\%) & $182(65.9)$ & N/A \\
\hline
\end{tabular}

ICU intensive care unit, $\mathrm{SICH}$ spontaneous intracerebral hemorrhage, $T B I$ traumatic brain injury

\section{Causes of critical illness}

Of the 1645 cases of critical illness, the most common cause of critical illness was SICH with coma (26\%, 17.6/ $100,000 \mathrm{PY})$, followed by acute TBI with coma $(16.8 \%$, $11.4 / 100,000 \mathrm{PY})$, heart failure/cardiovascular crisis $(8.5 \%$, 5.8/100,000 PY), trauma (7.4\%, 5.0/100,000 PY), cerebral infarction with coma $(7.3 \%, 5.0 / 100,000 \mathrm{PY})$, respiratory failure $(5.8 \%, 4.0 / 100,000 \mathrm{PY})$, post-surgery complication or intervention $(5.4 \%, 3.7 / 100,000 \mathrm{PY})$, pesticide/drug poisoning (4.4\%, 3.0/100,000 PY), metabolic dysfunction (3.7\%, 2.5/100,000 PY), and gastrointestinal bleeding with shock $(3.4 \%, 2.3 / 100,000 \mathrm{PY})$. Other causes of critical illness were less frequent (Fig. 1).

\section{Incidence of death from critical illness}

Four hundred eighty-nine deaths were reported in the ICU within the first 7 days of admission, with a rate of 20.2/100,000 PY. Males were at higher risk for this outcome than females $(313 / 1015,13.0 / 100,000$ PY vs. $176 /$ 630, 7.4/100,000 PY, respectively; $p<0.005$ ), and older patients $(>65 \mathrm{y}$ old) were at higher risk than younger patents ( 15 y to 65 y old) (243/701, 10/100,000 PY vs. 246/ 944, 1/100,000 PY, respectively; $p<0.0001$ ). (Table 3).

\section{Causes of death from critical illness in the ICU}

The causes of death from critical illness within the first 7 days of admission to the ICU were determined. The most common cause of death for ICU patients was SICH (180 patients, 7.4/100,000 PY), followed by acute TBI (4.2/100,000 PY), heart failure/cardiovascular crisis (2.5/ $100,000 \mathrm{PY})$, respiratory failure $(1.2 / 100,000 \mathrm{PY})$, cerebral 


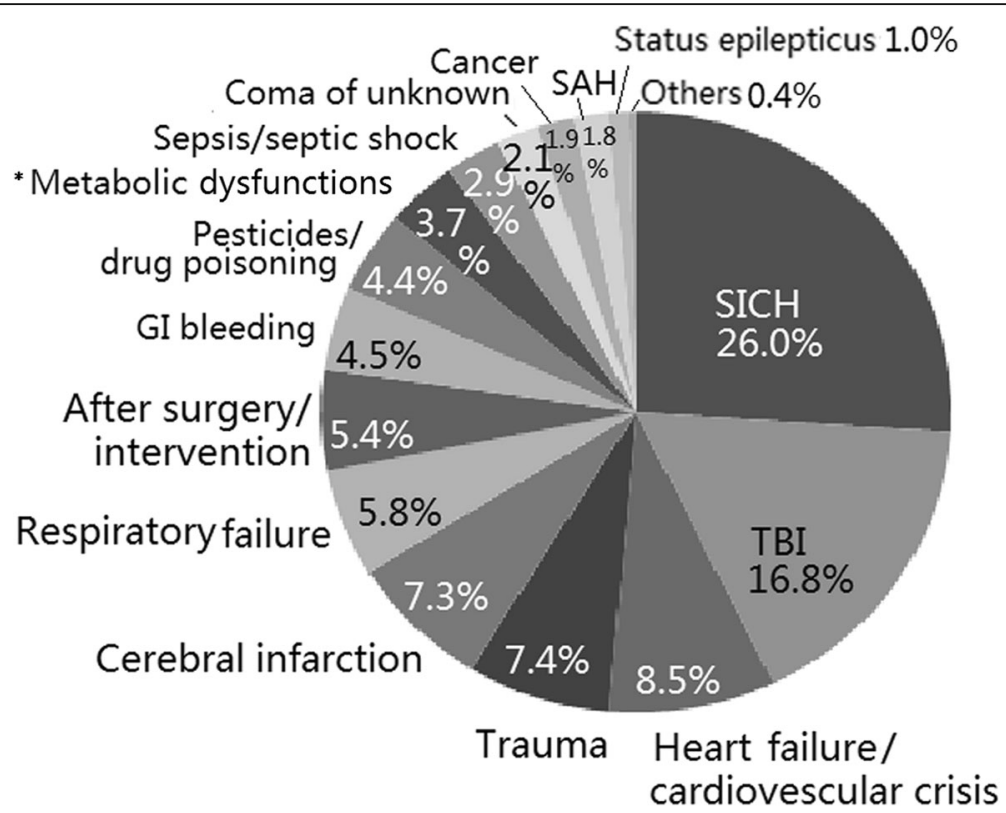

Fig. 1 The causes of critical illness in a northern China ICU. *Metabolic dysfunctions: including hypoglycemia, diabetic ketoacidosis, hyperglycemic nonketotic hyperosmolar states, kedney failure or uremia, hepatic encephalopathy, heat stroke, anoxia, and electrolyte dysfunction, etc.

infarction (0.9/100,000 PY), gastrointestinal bleeding (0.9/ 100,000 PY), sepsis/septic shock (0.9/100,000 PY), coma of unknown origin $(0.4 / 100,000 \mathrm{PY})$, pesticide poisoning $(0.5 / 100,000 \mathrm{PY})$, other traumas $(0.3 / 100,000 \mathrm{PY})$, cancer (0.3/100,000 PY), SAH $(0.3 / 100,000$ PY), metabolic dysfunction $(0.1 / 100,000 \mathrm{PY})$, and status epilepticus (0.04/ 100,000 PY) (Table 3).

Risk of death within 7 days of admission for the geriatric group vs. the non-geriatric group

Using a logistic regression analysis of the same study population, we compared the risk of death within 7 days of admission between the geriatric group and the non-geriatric group (Table 4). The risks of death from TBI (RR, 1.7; 95\% CI, 1.034-2.635; $p<0.05$ ), cerebral infarction (RR, $0.15 ; 95 \% \mathrm{CI}, 0.050-0.486 ; p<0.0005$ ), heart failure/cardiovascular crisis (RR, $0.2 ; 95 \% \mathrm{CI}$, $0.083-0.484 ; p<0.0005$ ), and respiratory failure (RR, 0.35 ; 95\% CI, 0.185-0.784; $p<0.005$ ) were higher in the geriatric group than in the non-geriatric group. The risks of death from $\mathrm{SICH}$, cardiac arrest with resuscitation, gastrointestinal bleeding, sepsis/septic shock, pesticide poisoning, and coma of unknown origin were not significantly different between the two age groups.

\section{Discussion}

In previous epidemiological surveys of prehospital emergency care, altered mental status [7] and trauma [8] have been reported to have the highest incidence rates. However, this study found that the incidences of these ailments among critically ill patients in the ICU were different from those observed in previous prehospital emergency care studies. We found that stroke (35.1\%, 23.8/100,000 PY) had the highest incidence rate, followed by trauma and TBI $(24.1 \%, 16.4 / 100,000 \mathrm{PY})$. The latter incidence may be due to the number of mild condition patients with prehospital trauma and TBI that may have been managed outside the ICU. This has been confirmed by a recent study that reported that only $20 \%$ of TBI cases account for admission to the ICU [10]. Conversely, epidemiological studies have confirmed that the incidence [11] and mortality rate for stroke are very high in China [12]. Therefore, it is likely that the care of patients with stroke has become a primary objective of ICU management.

The incidence of $\mathrm{SICH}$ varies in countries around the world [13], but recent studies have confirmed that the $\mathrm{SICH}$ incidence rate is highest in Asians (40.8-51.8/ 100,000 PY) $[13,14]$. According to our study, SICH is a main cause of critical illness among patients admitted to the ICU, which suggests that more than $1 / 3$ of patients with SICH need ICU care. Moreover, the fatality rate for patients with $\mathrm{SICH}$ within the first 7 days of admission was very high $(42.2 \%)$ and similar to the fatality rate after 1 month (43-52\%) that has been reported by other studies $[15,16]$.

TBI is the primary cause of injury-related death and disability [17], although its exact incidence is unclear. Our current study showed that TBI $(16.8 \%, 11.4 / 100,000$ PY) was the second most common cause of ICU 
Table 3 Incidence of death due to critical illness during the first 7 days in the ICU

\begin{tabular}{|c|c|c|c|c|}
\hline Charateristics & $\begin{array}{l}\text { Number of cases } \\
\text { in ICU/2 years }\end{array}$ & $\begin{array}{l}\text { Death during } \\
\text { the first } 7 \text { days } \\
\text { in the ICU/2 years }\end{array}$ & Percentage (\%) & $\begin{array}{l}\text { Mortality during } \\
\text { the first } 7 \\
\text { days/per } 100000 \\
\text { population } \\
\text { members per year }\end{array}$ \\
\hline Overall & 1645 & 489 & 29.7 & 20.2 \\
\hline \multicolumn{5}{|l|}{ Sex } \\
\hline Male & 1015 & 313 & $30.8 \S$ & 12.9 \\
\hline Female & 630 & 176 & $27.9 \S$ & 7.3 \\
\hline \multicolumn{5}{|l|}{ Age } \\
\hline$>65$ years & 701 & 243 & $34.7 \triangle$ & 10.0 \\
\hline 15 to 65 years & 994 & 246 & $24.7 \Delta$ & 1.0 \\
\hline \multicolumn{5}{|l|}{ Types of critical illness } \\
\hline $\mathrm{SICH}$ & 427 & 180 & 42.2 & 7.4 \\
\hline $\mathrm{TBI}$ & 276 & 101 & 36.6 & 4.2 \\
\hline Heart failure/cardiovescular & 140 & 61 & 43.6 & 2.5 \\
\hline Respiratory failure crisis & 96 & 28 & 29.2 & 1.2 \\
\hline After surgery or intervention & 89 & 10 & 11.2 & 0.4 \\
\hline Gl bleedingwith shock & 74 & 22 & 29.7 & 0.9 \\
\hline Cerebral infarction & 120 & 21 & 17.5 & 0.9 \\
\hline Sepsis / septic shock & 48 & 21 & 43.8 & 0.9 \\
\hline Pesticides/ drug poisoning & 73 & 11 & 15.1 & 0.5 \\
\hline Coma of unknown origin & 35 & 9 & 25.7 & 0.4 \\
\hline Trauma & 121 & 8 & 6.6 & 0.3 \\
\hline Any cancer & 32 & 7 & 21.9 & 0.3 \\
\hline SAH & 30 & 7 & 23.3 & 0.3 \\
\hline Metabolic dysfunction & 61 & 2 & 3.3 & 0.1 \\
\hline Status epilepticus & 16 & 1 & 6.2 & 0.04 \\
\hline Other & 7 & 0 & 0 & 0.0 \\
\hline
\end{tabular}

$\S p<0.005 ; \Delta p<0.0001$

$I C U$ intensive care unit, $S I C H$ spontaneous intracerebral hemorrhage, $T B I$ traumatic brain injury

admission. TBI has a mortality rate of approximately $40.0 \%$ [18] and a disability rate of $57.4 \%$ [19]. Moreover, our data showed that the fatality rate within the first 7 days of admission was also high in cases of TBI (36.6\%). However, the risks of death from TBI, heart failure/myocardial infarction, severe cerebral infarction, and respiratory failure were significantly higher

Table 4 Logistic regression analysis of the risk of death comparing the geriatric group and non-geriatric group during the first 7 days in the ICU

\begin{tabular}{llll}
\hline Critical illness & RR & $95 \% \mathrm{Cl}$ & $p$ Value \\
\hline TBI & 1.7 & $1.034-2.635$ & 0.034 \\
Heart failure/cardiovascular crisis & 0.2 & $0.082-0.483$ & 0.000 \\
Cerebral infarction & 0.15 & $0.049-0.460$ & 0.001 \\
Respiratory failure & 0.35 & $0.159-0.790$ & 0.011 \\
\hline
\end{tabular}

$I C U$ intensive care unit, $R R$ risk ratio, $C l$ confidence intervals, $T B I$ traumatic brain injury in the geriatric group than in the non-geriatric group. This finding indicates that older age is an important risk factor for death from most critical illnesses in the general ICU, which is consistent with a previous study [20] and may be related to that the older patients is more likely to develop an acutely fatal multiple organ failure [21]. On the contrary, the risk of death from $\mathrm{SICH}$ in the two groups was similar, and the $\mathrm{SICH}$ incidence results suggested a trend toward an increase in the younger population. This has been confirmed by one recent study [22].

Prior studies have shown that sepsis and septic shock account for $10 \%$ of ICU cases [23], whereas this study identified only 48 such cases (2.9\%). Because most sepsis or septic shock diagnoses are secondary to another disease, our result may be related to our study criteria, which examined only the first diagnosis (primary disease). These patients had been transferred to specialist 
wards or information on sepsis/septic shock had not been included in the diagnosis.

Surprisingly, the combined incidence of SICH and TBI was almost equal to the sum of the general ICU admissions for other critical patients. This strongly suggests that addressing these two critical diseases should be a public health priority and is deserving of further attention.

Although this study was conducted in one ICU, this ICU was the county's only ICU with a referral center. Therefore, we believe that our data are informative because the results of this study are more likely to represent the true epidemic spectrum of critical illness. However, certain limitations should be acknowledged. First, although this was a prospective registration, a small number of critically ill patients may be underrepresented due to a lack of standardized criteria for defining critical illness in this population. Second, because our registration only selected a sole primary diagnosis in the ICU, some patients with sequential liver or renal failure were not documented. This may have been the cause of the low frequencies of liver and renal failures that we observed. Additionally, the causes of coma were difficult to identify because numerous comatose patients had been intubated and could not consent to brain magnetic resonance examination. However, patients with unexplained comas were rare, so this was unlikely to produce a bias in the population of critically ill patients with neurological conditions.

In conclusion, the rate of critical illness was high in Shuyang County in northern China. The most common illnesses that required care in the ICU were SICH and TBI, and both of these critical illnesses carried a higher risk of death than other illnesses. This strongly suggests that addressing these two conditions should be a public health priority and is deserving of further attention.

\section{Abbreviations}

APACHE II: Acute physiology and chronic health evaluation II; GCS: Glasgow coma scale; ICU: Intensive care unit; SICH: Spontaneous intracerebral hemorrhage; TBI: Traumatic brain injury

\section{Funding}

This work is supported by a grant from the Medical Research Council, affiliated Shuyang People's Hospital, Xuzhou Medical University (Clinical Key Specialty Construction Project of Jiangsu Provence,20160017).

\section{Availability of data and materials}

The datasets used and/or analyzed during the current study are available from the corresponding author upon reasonable request.

\section{Authors' contributions}

ZYT and TDM were responsible for the study concept and design. ZYT, TDM, WSD, YS, XBW, and YCX were responsible for data acquisition and analysis. ZYT, TDM, WSD, YS, and YCX. were responsible for drafting the manuscript. All authors read and approved the final manuscript.

\section{Ethics approval and consent to participate}

The Ethical Committee on Clinical Research of the Shuyang People's Hospital, China, approved the study. The study was in full compliance with the Helsinki declaration, and written informed consent was obtained from the patient's nearest relative or a person who had been designated to give consent on admission of the patient.

\section{Consent for publication}

Not applicable.

\section{Competing interests}

The authors declare that they have no competing interests.

\section{Publisher's Note}

Springer Nature remains neutral with regard to jurisdictional claims in published maps and institutional affiliations.

\section{Author details}

${ }^{1}$ Department of Surgery, Affiliated Shuyang Hospital, Xuzhou Medical University, Xuzhou, Jiangsu, China. ${ }^{2}$ Department of Neurology, Affiliated Shuyang Hospital, Xuzhou Medical University, Xuzhou, Jiangsu, China. ${ }^{3}$ Department of Intensive Care Medicine, Affiliated Shuyang Hospital, Xuzhou Medical University, Xuzhou, Jiangsu, China

Received: 28 November 2017 Accepted: 15 August 2018

Published online: 27 August 2018

\section{References}

1. Bral AL, Cerra FB. Multiple organ failure syndrome in 1990, systemic inflammatory response and organ dysfunction. JAMA. 1994;271:226-33.

2. Joynt GM, Gomersall CD, Tan P, Lee A, Cheng CA, Wong EL. Prospective evaluation of patients refused admission to an intensive care unit: triage, futility and outcome. Intensive Care Med. 2001;27(9):1459-65. pmid: 11685338. https://doi.org/10.1007/s001340101041.

3. Sinuff T, Kahnamoui K, Cook DJ, et al. Rationing critical care beds: a systematic review. Crit Care Med. 2004;32(7):1588-97. pmid:15241106. https://doi.org/10.1097/01.ccm.0000130175.38521.9f.

4. Adhikari NK, Fowler RA, Bhagwanjee S, et al. Critical care and the global burden of critical illness in adults. Lancet. 2010;376(9749):1339-46. https:// doi.org/10.1016/S0140-6736(10)60446-1.

5. Cerro G, Checkley W. Global analysis of critical care burden. Lancet Respir Med. 2014;2(5):343-4. https://doi.org/10.1016/\$2213-2600(14)70042-6.

6. Gomes B, Higginson IJ. Where people die (1974--2030): past trends, future projections and implications for care. Palliat Med. 2008;22(1):33-41. https:// doi.org/10.1177/0269216307084606.

7. Rosamond WD, Evenson KR, Schroeder EB, et al. Calling emergency medical services for acute stroke: a study of 9-1-1 tapes[J]. Prehospital emergency care. 2005;9(1):19-23. PMID: 16036823[PubMed - indexed for MEDLINE]

8. Román MI, de Miguel AG, Garrido PC, et al. Epidemiologic intervention framework of a prehospital emergency medical service. Prehosp Emerg Care. 2005;9(3):344-54.

9. Statistical Yearbook of Jiangsu Province in 2013. Jiangsu: Population Statistics office press; 2013. p. 1-56.

10. Hefny $A F$, Idris $\mathrm{K}$, Eid $\mathrm{HO}$, et al. Factors affecting mortality of critical care trauma patients. Afr Health Sci. 2013;13(3):731-5. https://doi.org/10. 4314/ahs.v13i3.30.

11. Sun $Y H$, Zhang GH, Hu R, Wang C. Epidemiological survey of cerebrovascular disease among population in Inner Mongolia autonomous region. Chin J Epidemiol. 2015;36:925-8.

12. Chen Z. The third cause of death among netionwide reprospective sample survey report. Beijing: Chinese Peking Union Medical College press; 2008. p. 8-14.

13. van Asch CJ, Luitse MJ, Rinkel GJ, van der Tweel I, Algra A, Klijn CJ. Incidence, case fatality, and functional outcome of intracerebral haemorrhage over time, according to age, sex, and ethnic origin: a systematic review and meta-analysis. The Lancet Neurology. 2010;9(2):167-76.

14. Chan CL, Ting HW, Huang HT. The incidence, hospital expenditure, and, 30 day and 1 year mortality rates of spontaneous intracerebral hemorrhage in Taiwan. J Clin Neurosci. 2014;21(1):91-4.

15. Fogelholm R, Avikainen S, Murros K. Prognostic value and determinants of first-day mean arterial pressure in spontaneous supratentorial intracerebral hemorrhage. Stroke. 1997;28:1396-400.

16. Broderick J, Connolly S, Feldmann E, et al. Guidelines for the management of spontaneous intracerebral hemorrhage in adults: 2007 update: a 
guideline from the American Heart Association /American Stroke Association stroke council, high blood pressure research council, and the quality of care and outcomes in research interdisciplinary working group. Circulation. 2007:116(16):e391-413.

17. Coronado VG, Xu L, Basavaraju SV, et al. Surveillance for traumatic brain injury-related deaths--United States, 1997-2007. MMWR Surveill Summ. 2011;60(5):1-32.

18. Iwashyna TJ, Deane AM. Individualizing endpoints in randomized clinical trials to better inform individual patient care: the TARGET proposal. Critical Care. 2016;20:1.

19. Harrison DA, Griggs KA, Prabhu G, et al. External validation and Reca libration of risk prediction models for acute traumatic brain injury among critically ill adult patients in the United Kingdom. J Neurotrauma. 2015;32(1):1522-37.

20. Taylor MD, Tracy JK, Meyer W, et al. Trauma in the elderly: intensive care unit resource use and outcome. J Trauma. 2002;53(3):407-14.

21. Broos PL, D'Hoore A, Vanderschot $\mathrm{P}$, et al. Multiple trauma in patients of 65 and over. Injury patterns. Factors influencing outcome. The importance of an aggressive care. Acta Chir Belg. 1993;93(3):126-30.

22. Wang J, Bai L, Shi M,et al. Trends in age of first-ever stroke following increased incidence and life expectancy in a low-income chinese population. Stroke.2016 11. pii: STROKEAHA.115.012466. [Epub ahead of print].

23. Angus DC, Linde-Zwirble WT, Lidicker J, Clermont G, Carcillo J, Pinsky MR. Epidemiology of severe sepsis in the United States: analysis of incidence, outcome, and associated costs of care. Crit Care Med. 2001;29:1303-131.

Ready to submit your research? Choose BMC and benefit from:

- fast, convenient online submission

- thorough peer review by experienced researchers in your field

- rapid publication on acceptance

- support for research data, including large and complex data types

- gold Open Access which fosters wider collaboration and increased citations

- maximum visibility for your research: over $100 \mathrm{M}$ website views per year

At $\mathrm{BMC}$, research is always in progress.

Learn more biomedcentral.com/submissions 